\title{
An Approach to External Interference in Learning Motivation
}

\author{
Lingling Zhang ${ }^{1, a}$, Hongbo $\mathrm{Ma}^{2, \mathrm{~b}}$ \\ ${ }^{1,2}$ The Engineeringand Technical College of Chengdu University of Technology, Leshan, China \\ a, bemail:515851377@qq.com
}

Keywords: Learning motivation; Perceived self-efficacy; Appreciation education

\begin{abstract}
The key to the external interference in learning motivation lies in the motives and excitation. Cultivation of learning motivation focuses on shaping the value and the correct encouragement education can improve the learners' self-expectancy. Learning excitation is an art relying on the educators' creative application of the excitation principles.
\end{abstract}

\section{Introduction}

Many parents and teachers take it for granted that the students should naturally accept the idea of "students should work hard carefully in learning" and implement it in their action so that they should take in the knowledge taught to them the same way as the sponge absorbs water according to the teaching goal and learning mode designed by the school. The parents and teachers should do nothing but get disappointed and make criticisms in face of some "different" students who are not fond of learning.

Students differ in aptitude, living environment, experience and understanding of the society and life, so they have different expectations of the future and earning goals and attitude, thus showing different leaning behaviors. Unlike the bus which has fixed routes and operation modes, the school cannot take every passenger to his required destination or make everyone feel comfortable during the travel. Kindergartens, primary schools, middle schools and colleges function in one's growth at a certain phase. They just act according to the requirement of the superior management department and provide the students with designed teaching contents based on their ability (teaching ideals, faculties and school-running expenses and environment) with curriculum systems as the main carrier. Those educational organs are a kind of environment as well as resources. If the students cannot accept and adapt to the school teaching, they have to accept at the beginning of their life the fact of failures and backwardness. The failures and frustrations shall continue in the multi-step process of learning further and more complex knowledge, because their learning foundation is not solid.

Effective learning is initiated by the internal and external motives and orientated by the students' growth. It is a management process integrating all the management resources and functions. The students shall finally responsible for their own growth management, but the educators '(mainly parents and teachers) interference plays an important part in it before their mental and personality maturity. In our teaching system, the successful education may not lie in the success of few top students or the amount of knowledge taught to students but in the attention paid to those students who fail to adapt to the learning process and make more students wiling and ready to learn as well as good at learning. That is, the learning excitation can be realized through teaching processes, contents and methods. 


\section{Analysis of excitation factors}

Because of the individual internality in the process of learning, it fundamentally depends on the learners' internal excitation extent whether they are willing to make more efforts to learn. The excitation factors fall into the following two categories:

A. Learning motives. According to the author's study, the internal motives act on the learners most directly and permanently; they can also produce excitation factors for effective study results; the basical reason for the existence of the excitation role consists in the driving force produces when the individual tends to pursue an unsatisfied need ${ }^{[1]}$.

Curiosity and interest are the primitive driving forces for people to explore the unknown or the result. They are human instinct and fundamental excitation factors for effective learning. Learners interested in knowledge to be learned have more obvious excitation characteristics. They are inclined to find and study more voluntarily relevant information about learning and they feel excited, satisfied and happy in the process of learning instead of feeling painful after forced to learn.

However, it is rare occurrence that the interest and learning content are in the same direction. As a product of the development of long human civilization, the content of education and teaching originates from the accumulation in the civilization process. The systematicness, complexity and the extent of difficulty in learning are enough to fritter away the driving force brought by curiosity and interest. What's more, most people's interest is in simple, easy and relaxing things. Therefore, it needs not only instinct but also needs in more advanced thoughts and consciousness.

In the paper, curiosity and interest are viewed as instinct and natural physiological need, the sense of frustration and fear of low-level professional development as needs for safety, whether educational levels and academic levels are accepted by the society as need for social interaction; the senses of honor produced by success in learning and professional success in learning achievements as the need for respect, faith in life, the sense of mission and expectation of accomplishment as need for self-actualization. In this way, various motives are classified in the Maslow Hierarchy of Need Theory and the theory is used to study the law of excitation.

From the perspective of the hierarchy of need theory, human behaviors are decided by the competitive needs. Within the same period of time, the individual may have various needs, but only one takes the dominant place. Hierarchy of various needs form the shape of the pyramid from the lower level to the higher level, for the proportion of people is smaller when the need level is higher. Although the majority of people long for success and self-actualization, the difficulty in realizing the goal is greater when the need level is higher. Based on the feasibility of advanced needs, actual needs for delight in learning and overall consideration of the proportion of input and output, the advanced need are not converted into actual learning behaviors even though it is desired by most people ideologically.

B. Expectation excitation. The psychologist Vroom thinks man is rational and he shall decide whether to take certain actions according to the possibility of how well the expected results of a given behavior are going to match up with or eventually lead to the desired results and estimate of the importance of corresponding rewards. The motivation is shown in the following formula:

Motivation $=$ expectancy $\times$ instrumentality $\times$ valence

In the formula, expectancy refers to the subjective probability of realizing some performance level after one makes efforts; the instrumentality refers to the subjective probability that performance will be rewarded after the person reaches the performance level; valence is the significance associated by an individual about the expected outcome ${ }^{[2]}$.

Almost everyone has the needs at five levels mention above, but not all shall take the high-level 
need as the dominant need. The main reasons are:

First, the expectancy of excellent accomplishment. The idea of expectancy is similar to the perceived self-efficacy put forward by physiologist Bandura on social learning theory. It is the extent or strength of one's belief in one's own ability to complete tasks and reach goals (Bandura, 1994) ${ }^{[3]}$. The level of self-efficacy decides one's choice to regard it as a challenge and accept it or to regard it as difficulty and avoid it when one is faced with a new task in his development.

Second, instrumentality in which the corresponding result is obtained from the learning performance. In the long run, most people view learning as an individual investment and want to get more reward. However, when learners find their achievements in learning far less than those obtained by power, shortcuts or questionable means, they will lose heart and interest in hard working and their learning motive is drastically weakened. It involves another matter of the excitation of senses of fair.

Third, valence in which achievements are made by learning. Valence relates to the learning motives. The motives produce goals and the judgment standard to measure the goals is valence. From the analysis of motives, it can be known that the learning motives are diversified and the individual learners have different estimates for different motives, so they have different excitation strength ${ }^{[4]}$.

\section{Making proper use of external interference to promote learning motives}

The external interference in the learners is an art and the way of interference cannot be simply copying. The most important interference is to deal with motives and values and then self-efficacy.

A. Cultivating learning motives-the key lies in idea shaping. The specific motives of learning may vary in different situations. Yet the common characteristics of human nature exclude the choice of failure as the life goal for those immature individuals. Everyone expect success and the only difference is the specific target, scope and extent of "success". Everyone is some distance from the success goals and the gap shall be bridged through learning.

In motive cultivation, special attention shall be paid to developing and guiding value. The biggest problem at present is that many people, influenced by the actual social ideology in the transitional period, regard the amount of power and wealth as the criteria for success consciously or unconsciously. Their ultimate goal is to pursue and get power and wealth with the jungle rules as their life philosophy. They do not believe in justice, truth, rules and other people's meaning to themselves. Therefore, if there is a shortcut to obtain power and wealth without being responsible for the society or any other people, they cannot find any significance in hard working. All the ideas on "useless study" is based on the periodical result of obtaining power and wealth.

Man's most basic desires is undeniable. As a matter of fact, they are the so-called "invisible hands" which basically drives the people to take some actions. It is inevitable for man to get the greatest benefits with the least cost. The problem lies in the fact that the process of getting benefits in a long run and continuously. Anyone shall pay a higher price in the long run if he gets the short-term benefits in ways against the rule of social justice.

Cultivating learning motives involves not only the individuals' academic records, but also the educators' actions and it should arouse common attention of the whole society, for the learning motives are closely related to man's direction of value pursuit. Instead of the value off seeking nothing but benefits, the current education should teach the juveniles to think rationally and endow the criteria of "success" with abundant content—from the satisfaction of physical desires to the establishment of personality, from the fundamentals of survival to the meanings of existence and from pursuing individual freedom to fair and justice in the human society. Only in this way has learning the true meaning of helping the individuals grow up in an all-round way and perfect themselves constantly. To 
some extent, the mainstream learning motives of the social groups are one of the most important factors to judge whether the society is normal.

\section{B. Establishment of self-efficacy-differentiating appreciative education and frustration} education. After the problem of motives is solved, the biggest problem for learners in learning excitation is confidence, that is, the expectancy or self-efficacy. Everyone longs for success and are in fear failure when he sets out doing something. Appreciative education is promoted in recent years in education in China. This way has some merits when it is implemented as an educational idea and method. The appreciative education is premised on respecting students' personality and based on acknowledging and respecting differences. It tries to find the good of the students and fully affirm it to realize the "positive reinforcement" education of excitation ${ }^{[5]}$. In this method, the students affirm and believe in their choice of action and ability to act and their self-efficacy can be improved continuously. In practice, this way has got good results on quite a lot of students, but it still brings some problems. Some researchers find it will make the students have high self-evaluation and superiority, centers on themselves when doing things, tolerate none of the criticisms and even fail to correctly make judgments whether their words and actions accord with the social ethical standards if some educators blindly appreciate and praise the students and make improper positive evaluations even when the students fail. Gradually, they cannot endure various frustrations and setbacks in life ${ }^{[6]}$. Therefore, some scholars propose that the appreciative education combined with frustration education so that they can complement and reinforce each other ${ }^{[7]}$.

Actually, "appreciation" and "frustration" are not two opposite ideas: "frustration", similar to "failures", refers to the actual objective state that the individual fails to realize the goals and is opposite to "success". The core of the so-called "frustration education" is to teach students to correctly understand frustrations, prevent frustrations and treat frustrations and to strengthen their endurance capacity of frustrations. ${ }^{[8]}$. Yet "appreciation" means agreeing with or praising some behavior or its result and "despising" the other side. It is the refusal or devaluation of the individual's behavior or its result and a subjective expression of "disagreement". "Appreciative education" is a teaching method to guide the mental cognition and to excite the actions by positively reinforcing the student's behavior after showing "appreciation". Therefore, it can be seen that "frustration education" and "appreciative education" are in two different categories. "Frustration education" cannot solve the problems resulted from inappropriate appreciative education.

As the education idea and method to excite self-efficacy, appreciative education focuses on man's psychological needs and can effectively improve the learners' self-expectancy and increase their driving forces of learning. Yet as is the case with any effective medicine with some side effect in which different people and symptoms need different dosage and medicines, the complexity of mental behaviors make it impossible to show appreciation blindly to students to excite their learning motives. The lack of learning confidence may be resulted from the individual experience and self-recognition accumulated in various experiences. The appreciation from other people should be pertinent and based on mutual acceptance. It should be good enough to guide the students to establish new self-recognition.

Over-appreciation is improper. The key to appreciation is the educator's correct recognition of the level of self-efficacy. As for learners' mental state in the process of learning, it does not necessarily mean it is better to reach higher level of self-efficacy. If self-efficacy reaches certain level in which one can do anything and anything one does is right, the learners shall become self-conceited instead of self-confident and the motive force will be weaker. Therefore, when self-efficacy is above the normal standard, the educator should adjust the educational methods such as making an analysis of the reason 
for and inevitability and chance of the result, introducing new reference frames and setting higher goals and can make some frustrations for the learners to keep their self-efficacy at a normal and rational level.

\section{Educators}

From the above elaboration, it can be seen that the external interference in the learners' learning should be artistic and creative education. The educator should start from the actual situation of the learners, see clearly the objectives and directions of the education and choose and apply appropriate educational method, thus making high requests of the educators. As a matter of fact, when faced with a student suffering from school failure and analyzing his psychological process, the educators can attribute it to the improper education at earlier period. Yet the accumulation and irreversibility can result in the wasted efforts or no use.

This fact shows that the management of the juvenile growth depends on the educators' influence to a large extent under the premise that the social environment is uncontrollable and that education is a job of profession and society. The teachers can receive professional training on teaching laws and methods, but it remains a problem how to guarantee a teacher cares about every student with the consciousness and enterprise of educating students rather than engage in a career to make a living according to the superior executive orders and economic indexes for class fees. If the teacher does not have strong interest, firm convention and full absorption in work, it is impossible to create excellent artistic works.

Meanwhile, the family education the juveniles received at earlier time has more effects than school education, but the majority of the parents do not receive professional educational training and their education of the children relies mainly on common sense and their own education experience or the opposite. It is hard to imagine the result if a farmer with poor knowledge of farming cultivates the seedlings, a designer or constructor with poor knowledge on construction builds buildings or the parents knowing nothing about education teach their children according to their imagination. This is another important and tough problem.

In our educational system, how to make the educators improve their teaching methods and levels and stimulate the learners' learning drives under the premise that the teaching direction and content are not greatly changed is a systematic problem and is worth further contemplation by the social educators and man of insight on education.

\section{References}

[1] Zhang Lingling, Zhang Ting, Ma Hongbo, The 2D Classification of Learning Motivation and The Analysis on Its Mechanism of Action, ASSHM( 2013)91-96.

[2] Stephen P.Robbins, Mary Coulter. Management[M]. Pearson, 2011.

[3] Gao Shenchun.On Self-efficacy Theory [J]. Mental Development and Education, 2000, 1: 60-63.

[4] Zhang Lingling, Ma Hongbo. An Analysis to Effective Motivation System Based on Growth Management [J].Teaching and Management, 2014, 10.

[5] Zhang Cuiping. Theory and implementation Measures for Appreciative Education [D]. Shandong Normal College, 2006.

[6] Han Dengliang. Reflection of Appreciative Education Practice [J]. Contemporary Educational Science, 2005, 14. 
[7] Gao Xianhua. Strategies and Significance of Frustration Education and Appreciative Education [J]. Jilin Education, 2013, 5.

[8] Zhang Yaodong. On Frustration Education on College Students [J].Reform and Opening to the Ourside. 2010, 11. 